\title{
New distributional record of oblique-banded grouper, Epinephelus radiatus (Day, 1868) from the St. Martin Island, Bangladesh
}

\author{
Md. Abu HANIF ${ }^{1}$, Md. Rajib SHARKER ${ }^{1,2}$, Shaharior HOSSEN ${ }^{2}$, Moniruzzaman BIPU ${ }^{3}$ \\ Cite this article as: \\ Hanif, M.A., Sharker, M.R., Hossen, S., Bipu, M. (2021). New distributional record of oblique-banded groper, Epinephelus radiatus (Day, 1868) from the \\ St. Martin Island, Bangladesh. Aquatic Research, 4(2), 145-150. https://doi.org/10.3153/AR21011
}

${ }^{1}$ Patuakhali Science and Technology University, Department of Fisheries Biology and Genetics, Patuakhali-8602, Bangladesh

${ }^{2}$ Chonnam National University, College of Fisheries and Ocean Sciences, Department of Fisheries Science, 50 Daehakro, Yeosu, Jeonnam, 59626, Republic of Korea

${ }^{3}$ Riverine Station, Bangladesh Fisheries Research Institute (BFRI),

Chandpur-3600, Bangladesh

ORCID IDs of the author(s): M.A.H 0000-0002-9198-3879 M.R.S. 0000-0002-2423-5459 S.H. 0000-0003-3581-2271 M.B. 0000-0002-6154-8278

Submitted: 12.07 .2020

Revision requested: 14.08 .2020

Last revision received: 20.09 .2020 Accepted: 13.10 .2020

Published online: 06.02.2021

Correspondence:

Md. Abu HANIF

E-mail: mahanif.pstu@gmail.com

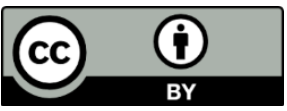

(C) 2021 The Author(s)

Available online at http://aquatres.scientificwebjournals.com

\begin{abstract}
Groupers are mostly found in the reef-associated marine habitat, of which some are pelagic and others are demersal. Recently, a grouper species called Oblique-banded grouper, Epinephelus radiatus (Day, 1868) was newly reported while conducting research work on the availability of reefassociated fishes in St. Martin Island. This species had never been reported to occur not only from this coral reef area but also from the water area of Bangladesh. E. radiatus was easily identified following morphological traits, especially color pattern. The findings of the present study added new distributional range for this grouper species from Bangladeshi water.
\end{abstract}

Keywords: First record, Grouper, Coral reef, St. Martin Island, Epinephelus radiatus 


\section{Introduction}

A coral reef is one of the most important biodiversity hotspots on earth, which contain some species-rich communities of marine fishes (Stuart-Smith et al. 2013, Rabosky et al. 2018, Atta et al. 2019). St. Martin's is the only coral belonging Island of Bangladesh endowed with vast marine and land resources having a global biodiversity significance. Molony et al. (2006) recorded a total of 225 fish species from this island of which most abundant fishes are Parrot, Snappers, Damsel, Surgeon, Butterfly, Emperors and Grouper. Thompson and Islam (2010) documented a list of 98 coral-associated fish species from this Island, including five species of grouper.

Groupers of the family Epinephelidae, earlier placed as a subfamily in Serranidae are of considerable economic value in tropical and subtropical countries (Rimmer and Glamuzina, 2017). The family comprises more than 160 species in 16 genera in the world (Tucker et al. 2016, Zhuang et al. 2013). Initially, Hossain (1969) listed eight species of epinephelids from the marine water of Bangladesh; however, nine more species had been added in the recent decade (Rahman et al. 2009; Thompson and Islam, 2010, Habib et al. 2017). By now, 17 species in 4 genera are available in this reef. Epinephelus radiatus of this family is distributed widely in the Indo-Pacific from East Africa to Tonga, including Zanzibar, Chagos, Lacadives, St. Brandon's Shoals, Maldives, Sri Lanka, India, Nazareth Bank, Sumatra, Fiji (Randall et al. 2003). It is a coral reef-associated species and inhabits relatively deep waters of rocky and coral reefs associated area in tropical region. It may also occur in marine protected areas in some parts of its range. However, juvenile $E$. radiatus mainly occur shallow rocky area while adults comparatively deeper water. This species is explicitly rare but abundantly found when it forms large schools. Although, the species is considered as a protogynous hermaphrodite; however, further research is needed to confirm this. The present paper reports a new record of $E$. radiatus for the first time from Bangladeshi water.

\section{Material and Methods}

In March 2018, three individuals of a species of grouper fish were sampled from a fisherman catch captured from the Saint Martin's Island (coordinate $20.611^{\circ} \mathrm{N}$ and
92.327 $7^{\circ}$ E) of Bangladesh (Figure 1) at a depth approximately $22 \mathrm{~m}$ during coral-associated fish diversity survey. Collected specimens were preserved in ice box and transported to the laboratory for identification. In the laboratory, fourteen morphometric measurements and seven meristic counts were taken from the collected species (Table 1) by using measuring board nearest to $0.1 \mathrm{~cm}$. A digital electric balance were used to measure the weight of sampled specimens up to $0.1 \mathrm{~g}$. The specimens were identified as $E$. radiatus according to traditional morphology-based taxonomic keys (Randall and Heemstra, 1991; Heemstra and Randall, 1993; Baldwin et al. 1994) and color pattern. The examined specimens (F1807SM-48) were deposited in the Fisheries Lab., Department of Fisheries Biology and Genetics, Patuakhali Science and Technology University, Patuakhali, Bangladesh.

\section{Results and Discussion}

Morphometric and meristic traits of E. radiatus are given in Table 1. E. radiatus is a fusiform fish. Both body and head are compressed; maxilla reaching to hind margin orbit; midlateral part of the lower jaw with two rows of palatine teeth (Figure 2); posterior margin of preopercle serrated and five enlarged serrae at the coner; three spines on opercle and one spine hided membrane; dorsal spines easily distinguished from rays; third dorsal spine longest; second and third anal spines subequal; pelvic fins not reaching anus; caudal fin convex to moderately rounded.

\section{Colour Pattern}

Immediately after capture, E. radiatus had greyish brown with five irregular oblique dark-edged brown bands (Figure 2 ); the first band curvilinearly extending from upper half of orbit to nape; second band branching from the first band just behind the eye, crossing anterior dorsal margin of the operculum, broadening on back and extending fourth dorsal spine; the third band began basally to the second band at opercular flap, expanding into posterior spinous of dorsal fin; fourth band runs from a rear end of dorsal fin, branching at medial side, with one branch going towards the origin of the anal fin, the other to a rear end of the base of the anal fin, the fifth band on the caudal peduncle, also branching ventrally. But after preservation, greyish brown with five irregular oblique darkedged brown bands paler than alive; expressly, a margin of body paled. 


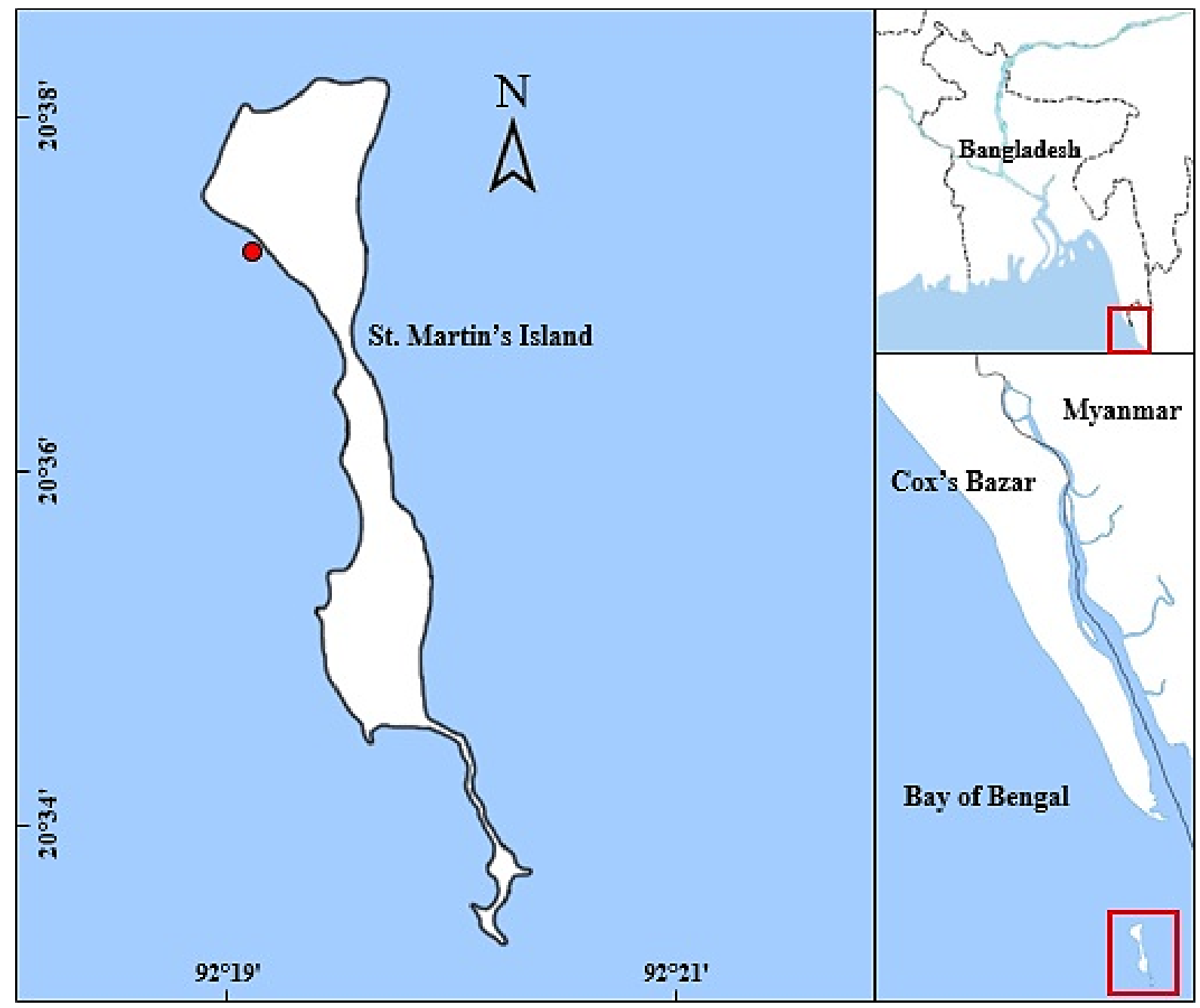

Figure 1. Sampled area of E. radiatus, St. Martin Island, Bangladesh

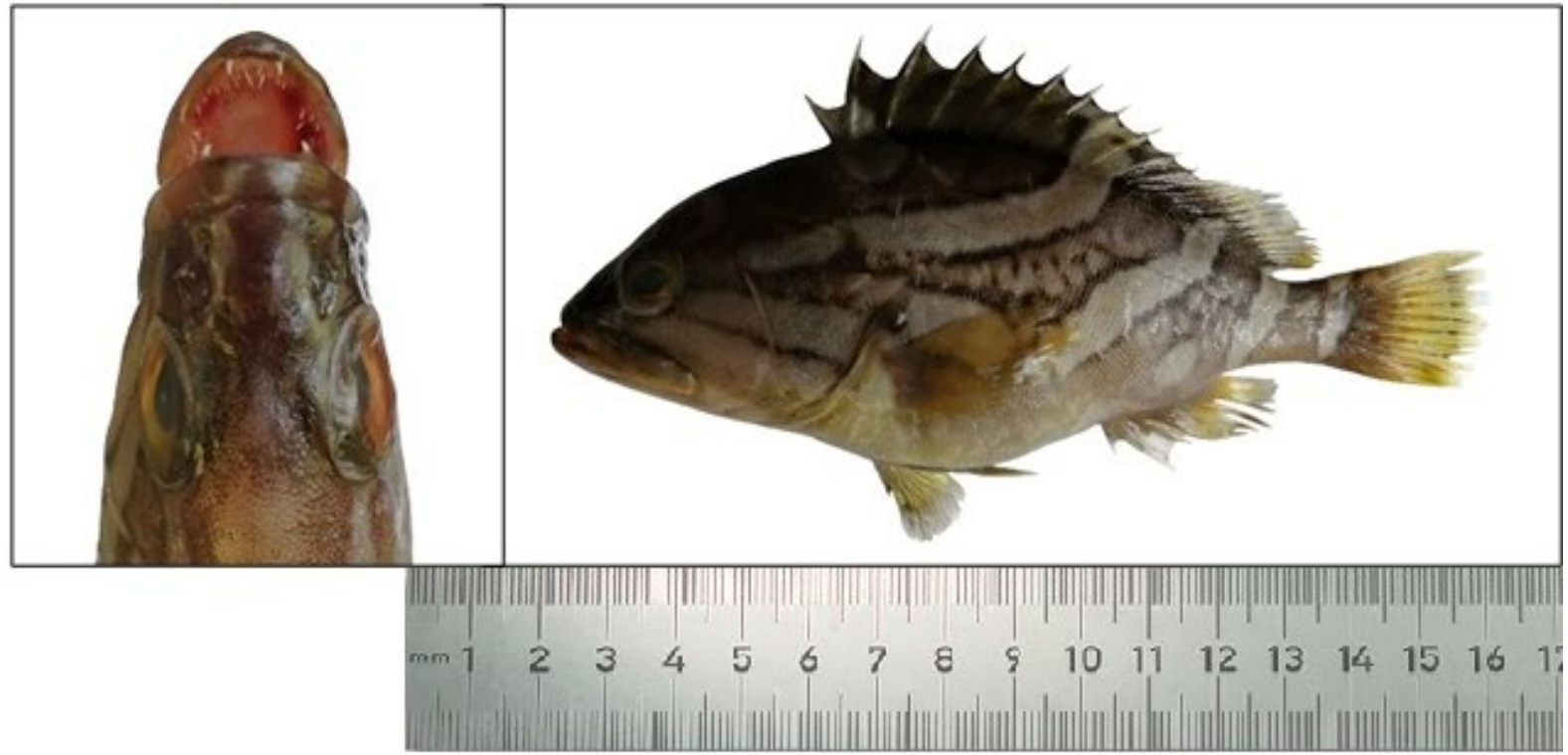

Figure 2. Lateral view with palatine teeth of E. radiatus collected from Saint Martin's Island 
Table 1. Comparison of morphometric measurements and meristic counts with the present study and published previous studies

\begin{tabular}{l|c|c|c|c}
\hline Parameter & \multicolumn{3}{|c|}{ Present study, $\mathbf{n}=\mathbf{3}$} & Han et al. (2014), \\
Morphometric characters & $\mathbf{1}^{\text {st }}$ specimen & $\mathbf{2}^{\text {nd }}$ specimen & $\mathbf{3}^{\text {rd }}$ specimen & - \\
\hline Total length (TL) & 13.7 & 14.2 & 14.1 & 371 \\
Standard length (SL) & 11.5 & 11.7 & 11.7 & 35.1 \\
Body depth (BD) & 5.1 & 5.2 & 5.0 & 18.7 \\
Body width (BW) & 1.9 & 2 & 2.1 & 40.7 \\
Head length (HL) & 4.3 & 4.4 & 4.4 & 7.9 \\
Inter-orbital length (IOL) & 0.9 & 0.9 & 0.9 & - \\
Eye diameter (ED) & 0.7 & 0.8 & 0.8 & 10.7 \\
Snout length (SL) & 1.0 & 1.1 & 1.1 & 33.1 \\
Pre-dorsal length & 4.1 & 4.3 & 4.2 & 38.7 \\
Pre-pectoral length & 4.4 & 4.5 & 4.5 & 71.7 \\
Pre-anal length & 7.6 & 7.8 & 7.9 & 19.0 \\
Upper jaw length & 1.7 & 1.8 & 1.8 & - \\
Caudal peduncle depth (CPD) & 1.0 & 1.1 & 1.0 & 11 \\
Meristic counts & \multicolumn{3}{|c|}{} \\
\hline Dorsal fin spines & 11 & 11 & 11 & 14 \\
Dorsal fin soft rays & 14 & 14 & 14 & 17 \\
Pectoral fin soft rays & 16 & 17 & 17 & - \\
Pelvic fin spine & 1 & 1 & 1 & - \\
Pelvic fin soft rays & 5 & 5 & 5 & 3 \\
Anal fin spines & 3 & 3 & 3 & - \\
Anal fin soft rays & 8 & 8 & 8 & \\
\hline
\end{tabular}

Generic identification of these Epinephelid was made following the diagnostic morphological characteristics described by Heemstra and Randall (1993). The members under the family Epinephelidae are typically identified by their color pattern, morphological characters and size of the fins, the shape and relative size of the head and various parts of the head and body (Elamin et al. 2011). Sometimes they exhibit different colours and morphological counts in the juvenile stage. However, a morphological feature, especially meristic counts, were in line with previous studies by Heemstra and Randall (1993), and Han et al., (2014). Previously, 15 species of Epinephelids under four genera, namely Cephalopholis (3 spp.), Cromileptes (1 sp.), Epinephelus (10 spp.), Plectropomus (1 spp.) which compare to very low found in Indian waters. Ranjan et al. (2017) estimated that, a total of 54 numbers of Epinephelids had been recorded from Indian waters.

Pisces are primarily mobile, and they may shift their location more quickly than species on land because they face fewer physical barriers (Pinsky et al. 2013). Also, many marine species, for instance; fish, do not have fixed nesting places or dwellings that might otherwise compel them to stay in one place. Species distribution is affected by a simple 'suitability' measure, established by the combination of unimodal responses to environmental variables (Meynard and Quinn, 2007; De-Marco et al. 2008). Climate changes are predicted to potentially affect population size, survival and distribution of organisms (Walther et al. 2002; Preuss et al. 2014; Su et al. 2015; Lu et al. 2015; Hanif et al. 2017; Siddik and Hanif, 2020). The highly discrete geographical distribution of species points towards a strong preference for a particular type of habitat (Hanif et al. 2019). Reef fish diversity of St. Martin Island of Bangladesh including other marine species, remains, to date, relatively unexplored (Hanif 2019). Currently, $12 \%$ of groupers worldwide are considered under threat of extinction (i.e. Critically Endangered, Endangered, or Vulnerable), with another $13 \%$ considered as Near Threatened (Castellanos-Galindo et al. 2018). The discovery of grouper species presented in this paper demonstrates the need for Bangladesh's reef fish and other understudied marine fauna available in Bangladesh, to be surveyed and documented, to produce an updated inventory of local marine species. There- 
fore, this present article has confirmed the presence of $E$. $r a-$ diatus in the Saint Martin's Island, Bay of Bengal and indicates the possibility of the existence of more species in the family Epinephelus in Bangladesh waters that have been overlooked in past surveys.

\section{Conclusion}

The present study confirms the occurrence of oblique-banded grouper, E. radiatus in the water area of Bangladesh. The findings of the study contribute to better understanding on biology, taxonomy, morphology, genetic and phylogenetic diversity as well as distribution of this species which would be helpful for sustainable management of this grouper species in Bangladesh.

\section{Compliance with Ethical Standard}

Conflict of interests: The authors declare that for this article they have no actual, potential or perceived conflict of interests.

Ethics committee approval: All authors declare that this study does not include any experiments with human or animal subjects.

Funding disclosure: -

Acknowledgments: We would like to thank the fisherman from the St. Martin Island who provided us captured specimen. We also extend our sincere thanks to Tomas (Tom) Tomascik, The University of British Columbia, Canada, who confirmed the authentic identity of the specimen.

Disclosure: -

\section{References}

Atta, C.J., Coker, D.J., Sinclair-Taylor, T.H., DiBattista, J.D., Kattan, A., Monroe, A.A., Berumen, M.L. (2019). Conspicuous and cryptic reef fishes from a unique and economically important region in the northern Red Sea. PLoS ONE, 14(10), e0223365.

https://doi.org/10.1371/journal.pone.0223365

Baldwin, C., Johnson, G., Heemstra, P. and Randall, J. (1994). FAO Species Catalogue. Groupers of the World (Family: Serranidae, Subfamily: Epinephelinae). An Annotated and Illustrated Catalogue of the Grouper, Rockcod, Hind, Coral Grouper, and Lyretail Species Known to Date. Copeia, 16(4), 1058.

https://doi.org/10.2307/1446737

De-Marco, P., Diniz-Filho, J.A.F., Bini, M.L. (2008). Spatial analysis improves species distribution modelling during range expansion. Biological Letter, 4, 577-580.

https://doi.org/10.1098/rsbl.2008.0210.
Elamin, S.M., Ambak, M.A., Samoilys, M.A., Hamza, M.E. (2011). Some Morphometric Relationships of Coral Trouts Plectropomus pessuliferus and Plectropomus areolatus Inhabiting Sudanese Red Sea. Advances in Environment Biology, 5(9), 2860-2865.

Habib, K.A., Kim, C.G., Oh, J., Neogi, A.K., Lee, Y.H. (2017). Aquatic Biodiversity of Sundarbans, Bangladesh. Korea Institute of Ocean Science and Technology (KIOST). $394 \mathrm{pp}$.

Han, S-H., Kim, M.J., Song, C.B. (2014). First Record of the Oblique-banded Grouper, Epinephelus radiatus (Perciformes: Serranidae) from Korea. Korean Journal of Ichthyology, 26(2), 143-146.

Hanif, M.A. (2019). First record of blue mackerel, Scomber australasicus (Pisces: Scombridae) in the Bay of Bengal, Bangladesh. Aquatic Research, 2(4), 211-215. https://doi.org/10.3153/AR19020

Hanif, M.A., Siddik, M.A.B., Nahar, A., Chaklader, M.R. Fotedar, R. (2017). A new distribution of the buffon's river garfish, Zenarchopterus buffonis (Valenciennes, 1847) in the coastal rivers of Bangladesh. Journal of Applied Ichthyology, 33, 1211-1214.

https://doi.org/10.1111/jai.13462

Heemstra, P.C., Randall, J.E. (1993). FAO species catalogue. Groupers of the world (Family Serranidae, Subfamily Epinephelinae) FAO Fisheries Synopsis. No. 125, Vol. 16. Rome, FAO. 296 p (382 pp). ISBN: 92-5-103125-8

Lu, X.M., Siemann, E., He, M.Y., Wei, H., Shao, X., Ding, J.Q. (2015). Climate warming increases biological controlagent impact on a non-target species. Ecology Letters, 18, 4856.

https://doi.org/10.1111/ele.12391

Meynard, C.N., Quinn, J.F. (2007). Predicting species distributions: a critical comparison of the most common statistical models using artificial species. Journal of Biogeography, $34,1455-1469$.

https://doi.org/10.1111/j.1365-2699.2007.01720.x

Molony, L-A and national project professional personnel. (2006). St. Martin's Island ECA conservation management plan. Coastal and wetland biodiversity management project, department of environment, Dhaka, Bangladesh. National geographic (nd). http://animals.nationalgeographic.com/ani$\underline{\text { mals }}$ 
Pinsky, M.L., Worm, B., Fogarty, M.J., Sarmiento, J.L., Levin, S.A. (2013). Marine taxa track local climate velocities. Science, 341, 1239-1242.

https://doi.org/10.1126/science.1239352

Preuss, S., Low, M., Cassel-Lundhagen, A., Berggren, A. (2014). Evaluating range-expansion models for calculating non-native species' expansion rate. Ecology and Evolution, 4(14), 2812-2822.

https://doi.org/10.1002/ece3.1106

Rabosky, D.L., Chang, J., Title, P.O., Cowman, P.F., Sallan, L., Friedman M., Kaschner, K., Garilao C., Near, T.J., Coll, M., Alfaro M.E. (2018). An inverse latitudinal gradient in speciation rate for marine fishes. Nature, 559, 392-395.

https://doi.org/10.1038/s41586-018-0273-1

Rahman, A.K.A., Kabir, S.M.H., Ahmad, M., Ahmed, A.T.A., Ahmed, Z.U., Begum, Z.N.T., Hasan, M.A., Khondker, M. (2009). Encyclopedia of Flora and Fauna of Bangladesh. Vol. 24. Marine Fishes. Asiatic Society of Bangladesh, Dhaka 485 pp.

Rajan, P.T., Mishra, S.S., Bineesh, K.K. (2017). First records of two species of groupers, Cephalopholis nigripinnis and Epinephelus retouti (Perciformes: Epinephelidae) from India, with a note on Epinephelids from Andaman and Nicobar Islands. Records of zoological Survey India, 117(3), 289294.

https://doi.org/10.26515/rzsi/v117/i3/2017/120972

Randall, J.E., Heemstra, P.C. (1991). Revision of Indo-Pacific groupers (Perciformes: Serranidae: Epinephelinae), with descriptions of five new species. Indo-Pacific Fish, 20, 332.

Randall, J.E., Williams, J.T., Smith, D.G., Kulbicki, M., Tham, G.M., Labrosse, P., Kronen, M., Clua, E., Mann, B.S. (2003). Checklist of the shore and epipelagic fishes of Tonga. Atoll Research Bulletin, 502, 1-35.

https://doi.org/10.5479/si.00775630.502.1

Rimmer M.A., Glamuzina B. (2017). A review of grouper (Family Serranidae: Subfamily Epinephelinae) aquaculture from a sustainability science perspective. Reviews in Aquaculture, 11, 58-87.

https://doi.org/10.1111/raq.12226

Rimmer, M., Glamuzina, B. (2017). A review of grouper (Family Serranidae: Subfamily Epinephelinae) aquaculture from a sustainability science perspective. Reviews in Aquaculture, 11(1), 58-87. https://doi.org/10.1111/raq.12226

Siddik, M.A.B., Hanif, M.A. (2020). Is the occurrence of dragonets fish (Callionymus carebares and Callionymus profundus) in the coastal waters of Bangladesh natural or incidental? Regional Studies in Marine Science, 38, 101361. https://doi.org/10.1016/j.rsma.2020.101361

Siddik, M.A.B., Hanif, M.A., Nahar, A., Chaklader, M.R. Kleindienst, R. (2017). First record of the razorbelly scad, Alepes kleinii (Bloch, 1793) (Carangidae) along the coast of Bangladesh. Marine Biodiversity Record, 10, 32.

https://doi.org/10.1186/s41200-017-0134-x

Stuart-Smith RD, Bates AE, Lefcheck JS, Duffy JE, Baker SC, Thomson RJ, Stuart-Smith, J.F., Hill, N.A., Kininmonth, S.J., Airoldi, L., Becerro, M.A., Campbell S.J., Dawson, T.P., Navarrete, S.A., Solar, G.A., Strain, E.M.A., Willis T.J., Edgar G.J. (2013). Integrating abundance and functional traits reveals new global hotspots of fish diversity. Nature, 501, 539-542.

https://doi.org/10.1038/nature12529

Su, J., Aryal, A., Nan, Z., Ji, W. (2015). Climate ChangeInduced Range Expansion of aSubterranean Rodent: Implications for Range land Management in Qinghai-Tibetan Plateau. PLoS ONE, 10(9), e0138969.

https://doi.org/10.1371/journal.pone.0138969

Thompson, P.M., Islam, M.A. (Eds.). (2010). Environmental Profile of St. Martin's Island, United Nations Develop-ment Programme, Dhaka. viii +150 pp. ISBN: 978-984-33-0779-8

Tucker, S.J., Kurniasih, E.M., Craig, M.T. (2016). A new species of grouper (Epinephelus,Epinephelidae) from the Indo-Pacific. Copeia, 104(3), 658-662.

https://doi.org/10.1643/CI-16-398

Walther, G.R., Post, E., Convey, P., Menzel, A., Parmesan, C., Beebee, T.J.C., Fromentin, J-M., HoeghGuldberg, O., Bairlein, F. (2002). Ecological responses to recent climate change. Nature, 416, 389-395.

https://doi.org/10.1038/416389a

Zhuang, X., Qu, M., Zhang, X., Ding, S. (2013). A comprehensive description and evolutionary analysis of 22 grouper (Perciformes, Epinephelidae) mitochondrial genomes with emphasis on two novelgenome organizations. PLOS ONE, 8(8), e73561.

https://doi.org/10.1371/journal.pone.0073561 